UC-20 and UC.25

Reporting Date: November 1975 Issued: April 1976

Fabrication of a Segmented Composite Stainless Steel1 Alumina Discharge Tube for a Theta-Pinch Coil

by

James M. Dickinson

Stephen D. Stoddard

James F. Muller 
This work was supported by the US Energy Research and Development Administration, Division of Controlled Thermonuclear Research.

Printed in the L'nited States of America. Available from National Tecinical Information Service

V.S. Department of Commerce

5285 Port Royal Road Springtield, VA 22161

Price: Printed Copy $\$ 3.50$ Nicrofiche $\$ 2.25$

This repart was prepared as an areoust of work npononret
bs the inuted sisters covernment. Neither the l'nited Staten nert the Inithed Hegtes Finerry Apesespeh and Devrlopment Ad.

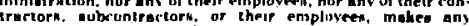
warrant expreas or implied, or asuumes sny lexal ligbiliti or

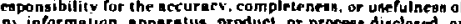
an infarmatuan. epperstus, product, or process diacloned. or
represents that ith uar would not infringe privately owned 


\title{
FABRICATION OF A SEGMENTED COMPOSITE STAINLESS STEEL- ALUMINA DISCHARGE TUBE FOR A THETA-PINCH COIL
}

by

James M. Dickinson, Stephen D. Stoddard, and James F. Muller

\begin{abstract}
An 80-mm-diam segmented discharge tube that simulated in a simplified way the blanket and first wall of the Reference ThetaPinch Reactor (RTPR) has been constructed. The segments were fabricated by plasma-arc spraying an alumina coating on tubular stainless steel trapezuids. These were laid up to form a cylinder that was contained in a fully dense alumina vacuum tube. The fabrication processes are discussed in detail.
\end{abstract}

\section{INTRODUCTION}

One of the many difficalt problems that must be studied before constructing fucure (post-Scyllac) theta-pinch reactors is the first wall, from both materials and fabrication standpoints. The tentative first wall and blanket designs for the Physics Test Reactor (PTR)* and the Reference Theta-Pinch Reactor (RTPR)? use modules having a segmented structure made of metal tubes coated with an insulating material.

So far there have been no tests of first walls that look like the proposed first walls for the PTR or RTPR design. All of the machines, including Scyllac, used monolithic quartz or alumina tubes to contain the plasma. A segmented linear discharge tube for a theta-pinch coil was constructed to provide data on the behavior of the plasma in such a tube, to provide data on materials under a plasma environment, and to advance the state of the art in manufacturirg such components.

The segmented linear discharge tube will be tested in a Scylla coil (known locally as the Thomson coil) now being used in LASL Physics-Division experiments. The discharge tube has 36 hollow 304 stainless steel trapezoids coated with 0.3 ium of a

*The PTR was an early version of the SFTR: and required a segmented first wall. The present design of the $S F T R$ does not require n segmented first wall. ceramic insulating material. For the first series of tests, the segmented tube need not be vacuum tight. The vacuum chamber will be an alumina tube just outside the trapezoidal segments of the discharge tube. Its effect on the plasma must also be established.

The first discharge tube was made using plasma. arc sprayed alumina as the insulator on 304 stainless steel tu'jing. Later tubes will have porcelain enamel coatings. Glazed alumina insulators are also being considered for future tests.

The fabrication operations of the discharge tubes discussed in this report are (1) general design and specifications, (2) fabrication of the metal trapezoidal tubing, (3) coating with an insulating material, (4) assembly of the trapezoids to form a disch:arge tube, and (5) testing of the assembly.

\section{DESIGN AND SPECIFICATIONS OF THE DISCHARGS TUBE}

The design of the discharge tube was controlled by several facturs. The $80-\mathrm{mm}-0 . \mathrm{d}$. by $500-\mathrm{mm}$-long dimensions were controlled by the size of the thetapinch coil (the Thomson coil) available for testing the discharge tube. In addition, the electrical parameters of the Thomson coil provided a lower limit on the number of segments required for the discharge tube due to azimuthal voltage considerations. 
Material selection for this and future segmented discharge tubes was based on the desire to tes: realistic material combinations for future reactors. Among the combinations considered were copperenamel, stainless steel-enamel, stainless steelalumina, and niobium-alumina. The latter received the most attention in the RTPR paper studies and also is being studied intensively from a radiation damage standpoint. However, because of cost, affinity for hydrogen, $\imath$ nd immediate as well as longterm availability of niobium, we decided to use stainless steel-alumina for the first discharge tube.

This will be more difficult than the niobium. alumina combination because of the adherence problems caused by the much larger mismatch in thermal expansion in the stainless steel-alumina system than occurs between niobium and alumina. An: technolog: developed for the stainless steelalumina system should be directly applicable to niobium-alumina, which is an easicr system to work with.

The discharge tube was desinned with $36500-\mathrm{mm}$ long alumina-coated hollow stainless steel trapezoidal segments laid up to form an annular first wall having a $69.2-\mathrm{mm}$ o.d. This segmented cylinder fit snugly inside a high-fired, fully dense alumina thin-walled (76.2-mm-o.d.) tube.

Figure 1 shows the segmented surface formed by the trapezoids inside the discharge tube. An alumina

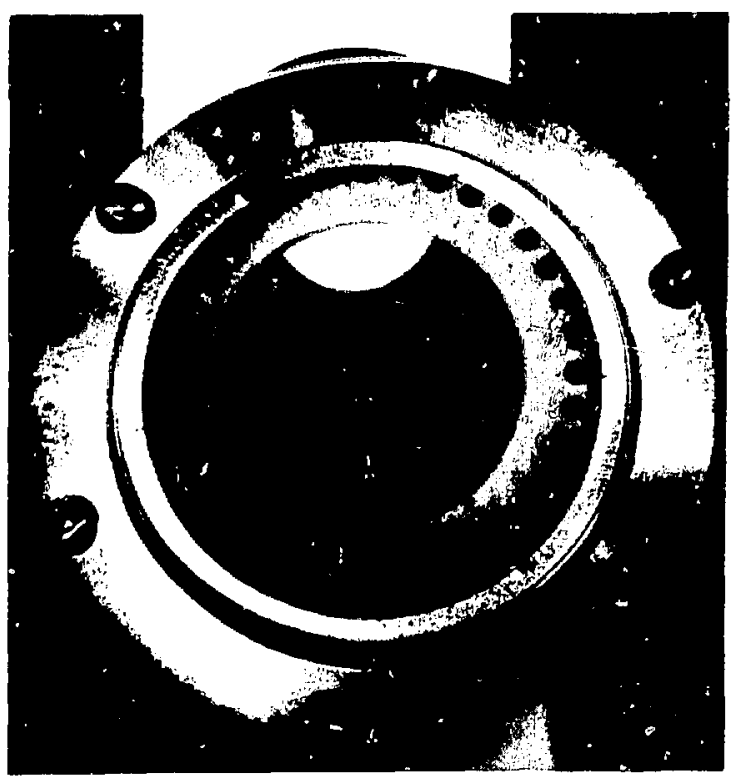

Fig. 1.

Interior of the completed segmented thetapinch discharge tube. end support holds the trapezoids in place. The 36 small holes through the support lead to the inside of the hollow trapezoids and serve as vacuum ports that allow the trapezoid tubes to be evacuated. A cross section of a trapezoidal segment of the tube is shown in Fig. 2.

The number of segments used in the discharge tube was based upon (1) the azimuthal voltage expected in the tests, (2) the azimuthal voltage expected in the PTR, and (3) the need for enough segments to approximate the $1=1,0$ (helicalbumpy) criterion that must be included in later discharge tubes and in the reactors.

The azimuthal voltage considerations indicated that a minimum of 7 seginents would be required for the Thomson coil test and a minimum of 40 tor the PTR test. The number of segments needed can be estimated by using the following equation.

$\mathrm{N}=\frac{2 \pi \mathrm{b} \mathrm{E}_{\theta}}{2 \delta \mathrm{E}_{\mathrm{D}}}$,

where

$\mathrm{N}=$ the number of segments required,

$\mathrm{E}_{\text {1) }}=$ the design dieiectric strength of the insulator in $\mathrm{kV} / \mathrm{cm}$,

$\mathrm{E}_{n}=$ azimuthal electricai field in $\mathrm{kV} / \mathrm{cm}$,

$b=$ minor radius of discharge tube,

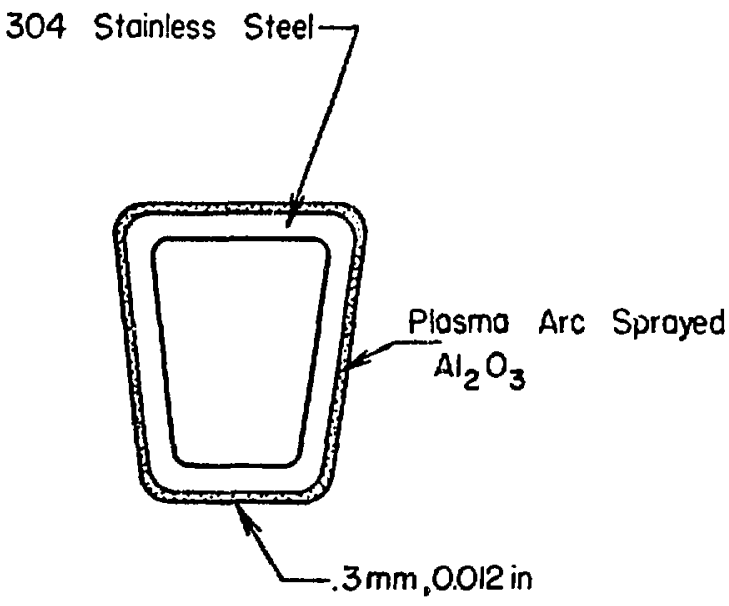

Fig. 2.

Cross section of one of the trapezoidal segments of the discharge tube. 
$\hat{o}=$ insulator thickness on each segment in cm for the Thomson coil and

$2 \pi b E_{4}=40 \mathrm{kV}$ and a value of $100 \mathrm{kV} / \mathrm{cm}$ was used for $\mathrm{E}_{1}$ of $\mathrm{Al}, \mathrm{O}_{3}$. The insulator thickness should be minimized for heat transfer reasons and a $0.03-\mathrm{cm}$ thickness was selected. The number of segments then can be found by

$$
\begin{aligned}
& N=\frac{(2 \pi b) E_{0}}{2 \delta E_{D}} \\
& N=\frac{40}{(2)(0.03)(100)} \approx 7 .
\end{aligned}
$$

A simila: calculation for the PTR, which has an $\mathrm{E}_{t}$ of $2 \mathrm{kV} / \mathrm{cm}$ and a minor radius $\mathrm{b}$ of $19 \mathrm{~cm}$, gives

$N=\frac{240}{2(0.03) 100}=40$ segments

In addition to the breakdown between segments, another mode of breakdown is possible on the first wall. Arcing could occur between edges of the trapezoidal segments through the plasmas when the plasma is in contact with the wall and when the azimuthal field is on. These conditions exist for a very small fraction of each cycle. Avaiiable information on this type of breakdown indicates only that it does not occur at low voltages. It is not known if this type of breakdown will occur and this will be determined when the discharge tube is tested.

We chose 36 as the number of segment 3 for the dis. charge tulve because (1) 36 is more than the minimum. number required for azimuthal voitage breakdown between segments for the Thomson coil experiment, (2) it approaches the number considered for the PTR design, (3) it is less than the "safe" number required by the edge breakdown mode just described and will give additional data in this area, and (4) it is a large enough number to allow a good approximate of the $r=(1,0)$ criterion when futi:se coils are fabricated.

Figure 3 shows a section through the discharge tube and shows the 36 insulator-coated metal trapezoids inside the $\mathrm{Al}_{2} \mathrm{O}_{3}$ vacuum sleeve.

\section{FABRICATION OF THE METAL TRAPEZOID SEGMENTS}

\section{A. General}

A detailed description of the fabrication process used to make the segmented discharge tube is given

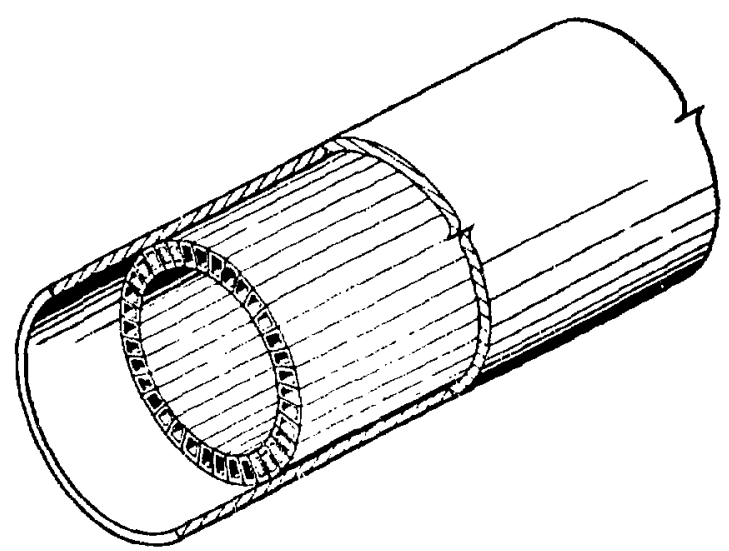

Fig. 3.

Segmented theta-pinch discharge tube.

in this section. The three operations discussed are (I) segment fabrication, (2) segment coating, and (.3) assenibly. We attempt to include enough detail t. enable the process to be repeated with a minimum of development effort.

As stated earlier, the discharge tub: had 36 metsi trapezoids coated with $A]_{2} \mathrm{O}_{3}$ arranged to form a hollow cylinder. Figure 4 show's a trapezoidal seg. ment of the discharge tube. Each segment had a trapezoidal cross section and it was necessary to hold tight tolerances on the cross section. An error of only $0.025 \mathrm{~mm}$ per segment could result in a cumulative error of almost a millimeter in the circumference of the segmented discharge tube, therefore -0.025 $+1) .000$ tolerances were specified. It sour became apparent that dimensional deviations tended to be random which allowed us to solect trapezoids that wo'ld make the final assembly possible. Therefore. the tolerances were relaxed to $-0.075+0.025 \mathrm{~mm}$. Part of the concern about tolerances was brought about by the probability that errors would be magnified by the subsequent coating operations which were difficult to control accurately.

The trapezoidal tubes were fabricated from 0.9 . $\mathrm{mm}(0.035$-in.) wall 7.9 -mm-diam (5/16-in. nominal) 304 stainless steel tubing using the following steps.

1. Size the tuhe to $7.95-\mathrm{mm}(0.313$-in. $)$ u.d.

2. Form the trapezoid in a single pass using a Turks Head.

3. Anneal the trapezoids.

4. Straigtiten the trapezoids.

\section{B. Tube Sizing Operations}

Early results in the trapezoid forming operation indicated that precisely sized starting stock was 


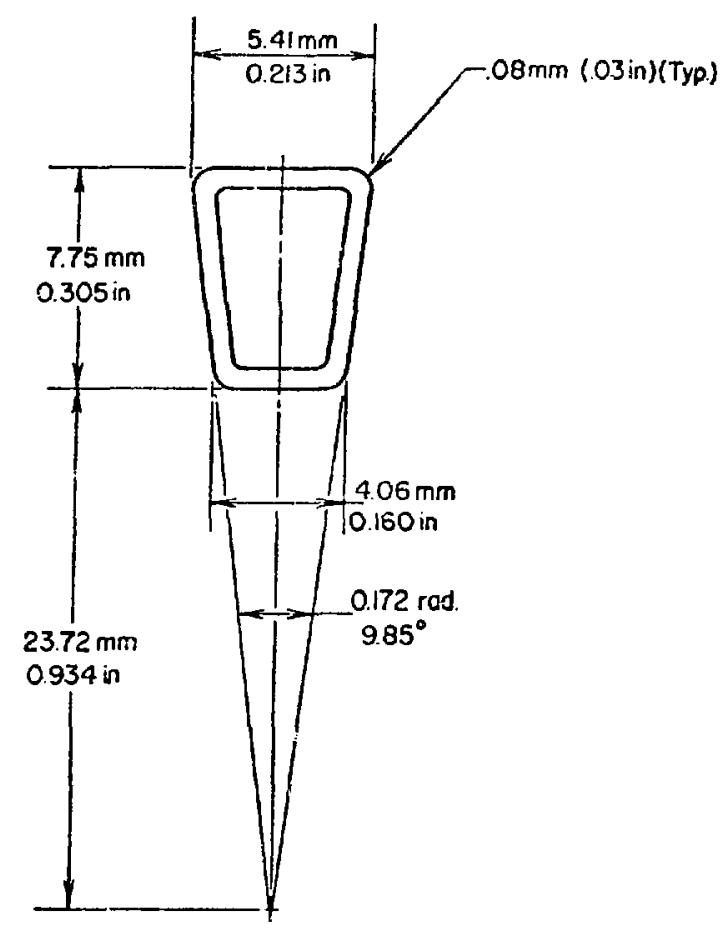

Fig. 4 .

Metal trapezoidal segment of the discharge tube.

necessary to obtair good dimensional tolerances in the finished trapezoids. Many of the $7.9-\mathrm{mm}$-diam tubes had a rippled surface caused by previous processing by the tubing manufacturer which adversely affected the forming operation on the trapezoids. Consequently, sizing operation was introduced as step No. 1

Approxinately 3-m-long lengths of nominal 7.9mm-diam tubing were point $x d$ and drawn through a. $7.95 \cdot \mathrm{mm}$-diam draw die at a rate of $\approx 1.7 \mathrm{~mm} / \mathrm{s}(4$ in./min) using no lubricaiton. This operation resulted in uniform round tibing ready for the trapezoid forming operation.

\section{Forming the Trapezoids}

The round tubing was formed inio a trapezoidal shape in a single pass by drawing it through a Turks Head. Figure 5 shows the Turks Head in operation with the round tubing going in and the trapezoidalshaped tubing coming out.

The Turks Head used was modified by redoing the roller arrangement to reduce play and ensure

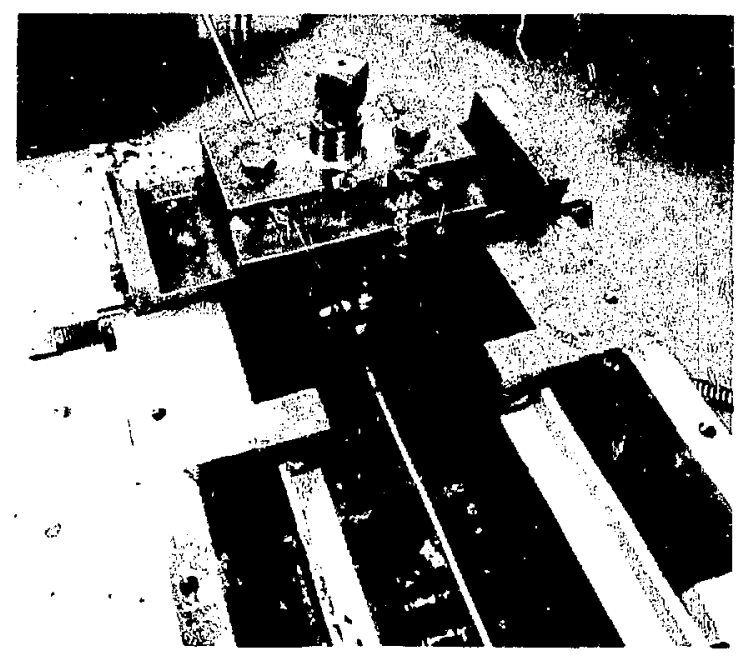

Fig. ;.

Tropezuidal forming operation.

perpendicularity of the roller axes. The vertical pair of the opposing rollers wie ground to a $10^{\circ}$ angle to form the trapezoidal shape shown in Fig. 6. This closeup of the rollers was taken from the input side. Several grinding and forming iterations were required to determine the final angle. A slight variation in springhack was noted between lots of tubing. and almost invariably there was some concavity on one of the long sides of the trapezoids which tended to vary from side to side along the $3-\mathrm{m}$ length of the tuke. The tubing used was half hard, and annealing

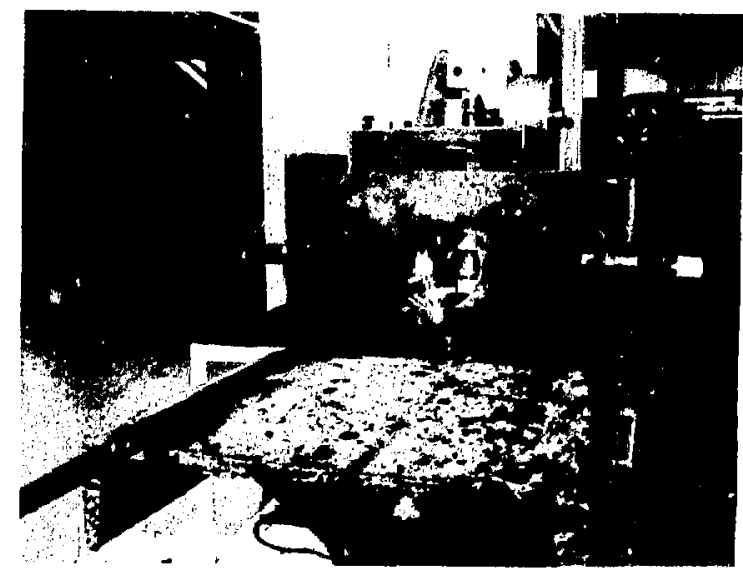

Fig. 6

Trapezoidal forming Turks Hersd. 
it before the Turks Head forming operation made the concavity problem worse.

The concavity was lister reduced by using certain lots of starting iubing. A multiple-pass Turks Head forming terhingue also promised concavity reduc. tion. This method involved rolling nearly to size on the two long faces only and then to size on all faces on the following pass. Simple stepwise reduction on all sides failed to help. These developments came too late 10 be used in the fabrication procedure, therefore concavities up to $0.05 \mathrm{~mm}$ were accepted.

\section{Annealing}

The trapezoidal-shaped tubes were annealed for $900 \mathrm{~s}(15 \mathrm{~min})$ at $1010^{\circ} \mathrm{C}$ in an argon at mosphere. A fixture that would hold three 3.05 - $m$-long trapezoids at a time was constructed ani used to contain the pieces during heat treatment. The furnace was a clamshell nichrome wound furnace constructed by joining three $457-\mathrm{mm}$-long. $76-\mathrm{mm}$-diam furnaces together end to end to form a 1.35 -m-long furnace having a common stainless steel furnace tube. The samples were inserted from one end and mover through the furnace in steps so that each area was in the hot zone, which was maintained at $1010^{\circ} \mathrm{C}$, for $900 \mathrm{~s}$.

\section{E. Straightening Operations}

The trapezoids generally warped slightly during fabricating operations and a straightening step was required. Several methods were considered.

A die straightening process was used successfully to straighten the trapezids after cutting them into $570 . n \mathrm{~m}$ lengths. The die used for the test was a block of graphite rontaining trapezoidal-shaped slots and was titted with a that graphite cover. After placing the tubes in the die and affixing the cover, the assembly was heated under argon for $900 \mathrm{~s}$ at $1010^{\circ} \mathrm{C}$. The resulting parts were very straight. The stainles: steel trapezoids were, of course, rather heavily carburized, but the experiment demonstrated the feasilbility of that straightening method at minimum expense for die construction.

Before making an expensive nickel base alloy straightening die, another method was tried that proved to be easier and faster. Therefore the die straightening concept was dropped. The new method involved stretching the trapezoids slightly after heating them to the plastic state.

The 3.05 -m-long tubes were set up in a draw bench so they could be stretched and heated simultaneously. An 800-A welding generator was used for the power source and the trapezoids were heated to a dull red heat by their self-resistance. During heating they were kept under tension by the operator who used force applied to the draw mechanism with a hand-held lever. When the aperatur felt the trapezoid relax, he turned off the power and the tube cooled rapidly while still being held under tension. In general. this process worked very well; however, occasionally it was necessary to repeat it, particularly if a badly warped tube was being straightened. The straight tubes were then cut into $560 \mathrm{~mm}$ lengths. A short sample was removed between each section for inspection to ensure that dimensional tolerances were met.

\section{F. Inspection}

The $560-\mathrm{mm}-$ long rods were inspected for straightness hy measuring their height above a flat table using a dial gauge. Measurements were made every $76 \mathrm{~mm}$ along the lengt $\mathrm{h}$ of the tubes and pieces that varted by more than $\pm 0.04 \mathrm{~mm}$ at any measuring station were restraightened. The trapezoid dimensions and angles were moasured on an EX. cell-o Model 30 Contour Projector, using the pieces cut from between the 560 -mm-long segments. Templates. $0.025 \mathrm{~mm}$ oversize and $0.076 \mathrm{~mm}$ undersize. were used as go-no-go gauges. If the sample was not within these tolerances, the adjoining 560 $\mathrm{mm}$ segments were discarded. Most of the specimens were within tolerances.

\section{G. Cleaning}

The 560 -mm-long segments were cleaned by a several-step process designed to ensure extremely clean surfaces for the ensuing coating operations. The trapezoids were first vapor degreased using trichloroethylene and then etched $600 \mathrm{~s}$ in $50^{\circ} ; \mathrm{HCl}$ containing a little hydrogen peroxide. After thorough rinsing. the parts were given two 60-s cycles in a Summa Polish bath, which was followed by a rinse, a dip in $50, \mathrm{HNO}_{3}$, and a final thorough rinse. The cleaned trapezoid specimens were packaged in tubular plastic envelopes.

\section{ALUMINA COATING THE TRAPEZOIDS BY PLASMA-ARC SPRAYING}

\section{A. General}

Coating a round tube or a flat surface by plasmaarc spraying is a relatively straighiforward opera. 
tion. A round tube can be coated by simultaneously rotatirig the specimen and traversing the spray gun while spraying. Simply traversing the gun back and forth while spraying can give a good uniform coating on a flat surface. However, rotating a trapezoidalshaped tube gives a nonuniform deposit caused by changing the distance and angle of the substrates to the nozzle. Therefore, we decided to use only a traversing motion.

To determine at what points on the surface of the trapezoids the gun should be aimed, a geometric approach was taken. By laying out the spray cone and trapezoids in various positions, the coated area of the trapezoid could be determized for any orientation. We were able to make a good "guess" from this information, and then by trial and error establish a spraying schedule. The process was further complicated by the fact that spray guns hiccough. They do not always spray the same amount of material in a given time, even though all parameters are maintained as constant as possible. We finally sprayed the trapezoids to about 80 to $90 \%$ of the required coating thickness according to the predetermined spraying schedule, and then measured the coating thickness both around and along the tube. The final few passes needed to bring the coating to the desired thickness were then made on the appropriate sides or corners of the irapezoids.

The remainder of this section discusses coating procedures in detail, including (1) powder used, (2) equipment used, (3) spraying parameters, (4) spraying procedure, (5) coating thickness determinations, (6) cutting the coated sections to length, and (7) coating the ends.

\section{B. Coating Equipment Used}

We used a Plasmadyne Model SG-1B snray gun operated from a 40-kW Plasmadyne PSG1-M power supply. The powder feeder was a Sylco model Mark IX used with argon gas.

The first spraying attempts were made with a hand-held gun and were successful, although the uniformity was somewhat less than desired. Consequently, a spraying machine was designed and constructed that allowed us to spray in a more uniform and reproducible manner (Fig. 7). It consists of a large rack equipped with rotatable specimen-holding collets, a spray gun traversing mechanism, and a specimen raising and lowering mechanism.

The trapezoid tubes to be coated were held hy two collets that fit inside the tube and could be rotated either mechanically or manually. Indicators allow the trapezoids to be lined up with the nozzle in 10 different rotational positions. The entire sample-

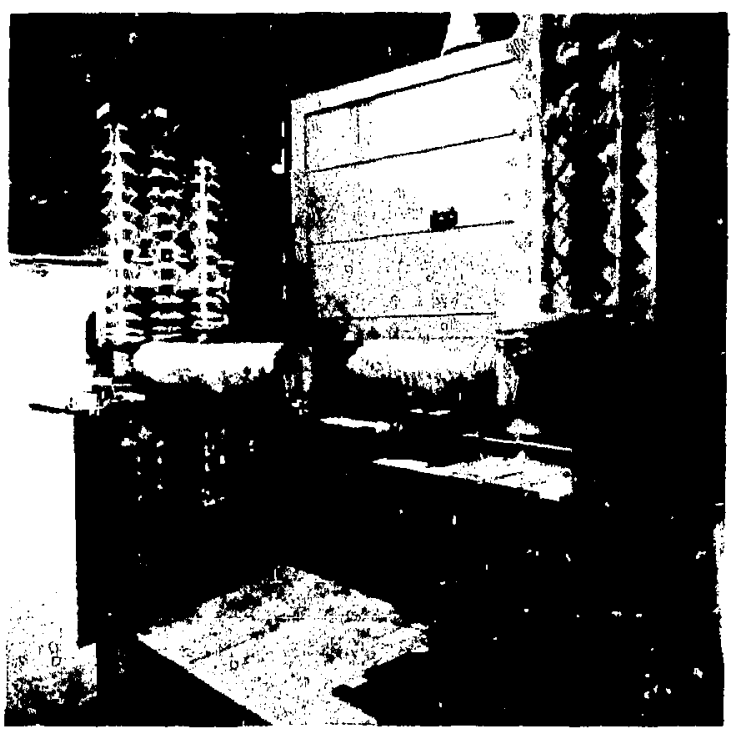

Fig. 7 .

Plasma-arc spraving apparatus.

holding mechanism could be raised or lowered to allow accurate alignment with the spray gun. The verticle movement required for the trapezoids was small and was measured using the dial gauge shown in Fig. 7.

The gun-traversing mechanism allowed the 560$\mathrm{mm}$ length of the trapezoid to be sprayed with a smooth linear motion that covered about $660 \mathrm{~mm}$. When the spray was off the sample, it was au! omatically reversed and a pass was made in the other direction again going beyond the end of the trapezoid before reversing. The traversing speed was controlled using a dc motor and a set of interchangeable gears. The number of spray passes was recorded by a counter that triggered with each traverse.

The bearings, slides, lead screws, and threads of the apparatus were protected from the abrasiveness of the alumina by plastic bellows covering much of the machine as shown in Fig. $?$. 
Envirnmental contamination was prevented by spraying directly into a filtered exhaust hood. There were, however, very high noise levels and ear protection was required for the operators.

A flame deflector similar to the one described by Abbatiello ${ }^{3}$ was used to minimize the substrate heating from the plasma. It consisted of a $6-\mathrm{mm}$ diam copper tube equipped with a slotted 0.5 - by 12 . $\mathrm{mm}$ nozzle aimed perpendicular to the plasma stream so that a gas exiting from the flame deflector would force the plasma downward. The argon gas pressure was adjusted to force the plasma to just miss the trapezoids and not seriously deflect the much heavier alumina particles.

\section{Alumina Powder Characteristics}

The alumina powder used for this project was identified as Norton Company $\mathrm{A}_{2}, \mathrm{O}_{3} \cdot 100$ lot No. ;8 500 AWIF. The powder was thoroughly characterized by us using such methods as metallography, sedigraph particle distribution measurements, density measurements, chemical analysis, BET surface area analysis, and $x$-ray studies.

The results of the spectrochemical analysis are shown in Table 1. Iron, silicon, and zirconium were the main impurities found. The $<$ signs indicate that the amount of the element present, if any, was below the detection limits of the method used. Analyses were made only for those elements includ. ed in Table 1.

The as-received alumina powder was shown to be alpha alumina by $x$-ray diffraction examinations.

Density measurements were made according to ASTM specification B329. The bulk density was 1.16 $\mathrm{Mg} / \mathrm{m}^{3}$ (28.6\% of the theoretical value for alumina), the tap density was $1.99 \mathrm{Mg} / \mathrm{m}^{3}$ (49.1 theoretical), and the pynocometer density was $4.05 \mathrm{Mg} / \mathrm{m}^{3}$ (essentially the theoretical value).

Fisher subsieve size of the powder was measured according to ASTM specification B330 and was found to be $5.6 \mu \mathrm{m}$. As measured by the BET method, the surface area was $0.708 \mathrm{~m}^{2} / \mathrm{g}$.

A photomicrograph of the powder is shown in Fig. 8. The particles are angular and appear dense. The particle size distribution of the powder is skewed towards the larger size region. This is seen both in the photomicrograph and the sedigraph data shown in Fig. 9. The sedigraph data indicated that the powder has a mean particle size of $20.5 \mu \mathrm{m}$, a variance of $56.1 \mu \mathrm{m}$, and a surface area, which is calculated on the basis of spherical particles, of 0.2 $\mathrm{m}^{2} / \mathrm{g}$.

The powder characterization showed it to be a reasonable powder for plasma-arc spraying; however, it could have been improved by removing the "fines,"

TABLE I

SPECTROCHEMICAL ANALYSIS OF

$\mathrm{AL}_{2} \mathrm{O}_{3}$ POWDER USED

\begin{tabular}{|c|c|c|c|c|c|}
\hline Element & $\begin{array}{c}\text { Amount } \\
\text { Present } \\
\text { (ppm) }\end{array}$ & Element & $\begin{array}{l}\text { Amount } \\
\text { Present } \\
\text { (ppm) }\end{array}$ & Elemenx & $\begin{array}{c}\text { Amount } \\
\text { Present } \\
\text { (ppm) }\end{array}$ \\
\hline $\mathrm{Li}$ & $<10$ & $\mathrm{Fe}$ & 300 & $\mathrm{Ag}$ & $<$ \\
\hline $\mathrm{Be}$ & $<1$ & Co & $<3$ & $\mathrm{Cd}$ & $<$ \\
\hline B & $<$ & $\mathrm{Ni}$ & $<10$ & lr & $<$ \\
\hline $\mathrm{Na}$ & 30 & $\mathrm{Cu}$ & 10 & $\mathbf{S r}$ & $<3$ \\
\hline $\mathbf{M g}$ & $<10$ & $Z_{n}$ & $<100$ & $\mathrm{Sb}$ & $<10$ \\
\hline $\mathrm{Si}$ & 100 & $\mathrm{Ga}$ & $<10$ & $\mathrm{Te}$ & $<100$ \\
\hline $\mathbf{P}$ & $<300$ & Ge & $<10$ & Cs & $<100$ \\
\hline$K$ & $<30$ & As & $<100$ & $\mathrm{Ba}$ & $<10$ \\
\hline $\mathrm{Ca}$ & $<30$ & $\mathrm{Rb}$ & $<100$ & $\mathrm{Ge}$ & $<300$ \\
\hline $\mathrm{Ti}$ & 20 & Sn & $<10$ & $\mathbf{W}$ & $<100$ \\
\hline$v$ & 10 & $\mathrm{Zr}$ & 100 & $\mathrm{Tl}$ & $<10$ \\
\hline $\mathrm{Cr}$ & 30 & $\mathrm{Nb}$ & $<100$ & $\mathbf{P b}$ & $<3$ \\
\hline $\mathbf{M n}$ & 3 & Mo & 3 & $\mathrm{Bj}$ & $<$ \\
\hline
\end{tabular}




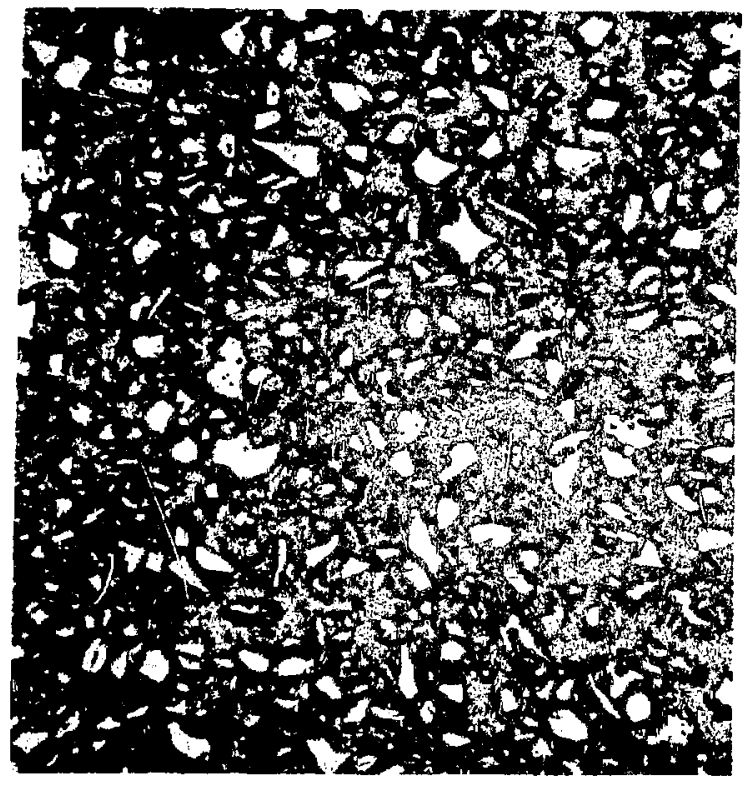

Fig. 8 .

Thostomicrostaph of the alumina pouder $(2.51) X)$.

AL 203-100 Sedigroon

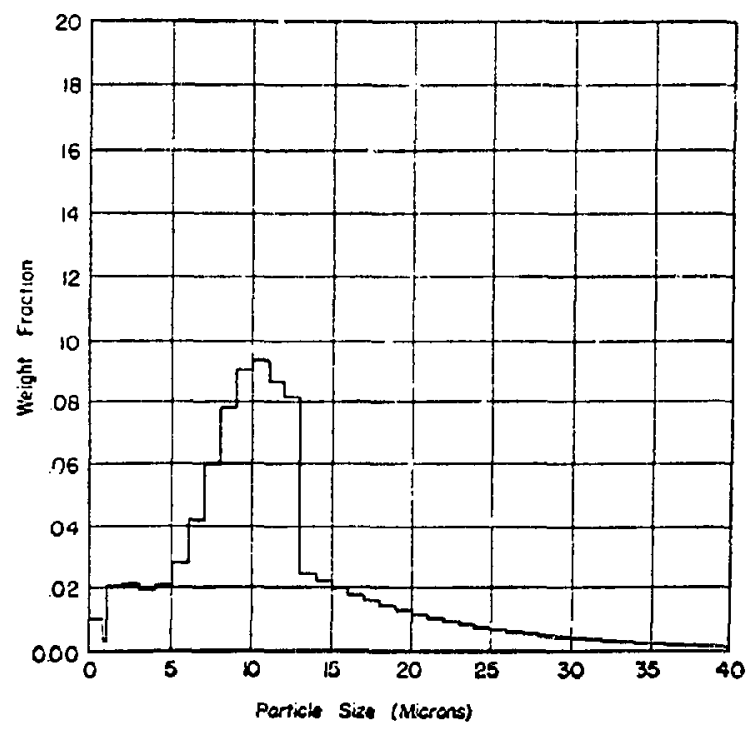

Fig. 9 .

Particle size distribution of the alumina pouder.

After the powder had been sprayed on the trapezoids, a radiography examination of the coating disclosed several high-density inclusions. X-ray Hurescence examinations indicated the presence of iron, copper, germanium, tin, zinc, niobiu:a. molybdenum, and lead. Magnetic separation and dry screening, separately and in combination, were evaluated in an effort to elimmate or at least to minimize these impurities. Because all the methods reduced both the inclusion content and the intensity of the $\mathrm{x}$-ray fluorescence peaks about an equal amount, the powder was screened through a 400 mesh screen before spraving the trapezoids for the discharge tube.

The impurity level of samples taken from the screened $\mathrm{Al}, \mathrm{O}$, stock, from the plasma spray gun hopper, and the nozzle of the spray gun were compared and found to be equivalent, which convinced us that the powder was not being contaminated during handling or spraying operations.

\section{Spraying Parameters}

There are several plasma-arc spraving parameters that must be kept within fairly small ranges and in balance to control the quality of plasma-arc sprayed coatings. Our data showed that, for this particular application and with alumina powder lot $500 \mathrm{~F}$, the operating conditions shown in Table II gave the best results.

\section{TABLE II}

OPERATING PARAMETERS FOR PLASMA-ARC SPRA.YING ALUMINA POWDER LOT 500F

\section{Parameter}

Gun-to-work distance

Plasma deflecto. -to-gun face

Plasma deflector air pressure

Gun traversc rate

Arc gas pressure

Arc gas flow rate

Arc amperage

Carrier gas pressure

Carrier gas at $11.8 \mathrm{~m}^{3} / \mathrm{s}$ flow rate

Feed screw speed setting

Vibrator setting

\author{
Optimum Values \\ $38 \mathrm{~mm}(1.5 \mathrm{in}$. \\ $19 \mathrm{~mm}(3 / 4 \mathrm{in}$ ) \\ $207 \mathrm{l}: \mathrm{Pa}(30 \mathrm{psi})$ \\ $4.5 .7 \mathrm{~mm} / \mathrm{s}(1.8 \mathrm{in.} / \mathrm{s})$ \\ $379 \mathrm{kPa}$ (55 psi) \\ $314 \mathrm{~cm}^{3} / \mathrm{s}$ (40 cfh) \\ $500 \mathrm{~A}$ \\ $138 \mathrm{kPa}(20 \mathrm{psi})$ \\ $157 \mathrm{~cm}^{3} / \mathrm{s}(20 \mathrm{cfh})$
}

75

60 


\section{E. Plasma-Arc Spraying Procedure}

The stainless steel trapezoidal-shaped tubes, which had been chemically cleaned after being fabricated, were grit blasted at $345 \mathrm{kPa}$ (50 psi) using 60-mesh alumina particles. This provided a clean roughened active surface just prior to spraying and helped increase adhesion between the coating and the substrate. After grit blasting, the pieces were handled using clean cotton gloves.

Before selecting a spraying procedure, several experiments based on the geometrical relationships between the spray gun, gun position, and trapezoidal orientation were undertaken to determine the best ways to orient the trapezoids to produce uniform and reproducible coatings. Various combinations of spraying only on the faces, the corners, or combinations of both were evaluated. The procedures described in the remainder of this section were chosen for the production of the coated trapezoid tubes used for th discharge tube.

The grit-blasted trapezoids were placed in the collets of the spraying apparatus and the proper spraying parameters set on the control consoles. Most of the spraving was done with the trapezoid positioned so that the spray cone was bisected by the trapezoid oorners.

The numbers 1 through 8 in Fig. 10 show the various positions at which the spray gun could be aimed during the operation. The trapezoids were sprayed starting with the gun aimed at position two, five passes were made and then the trapezoid was rotated, between passes, so that position four faced the spray gun. It was then necessary to adjust the vertical position of the sample because the corners of

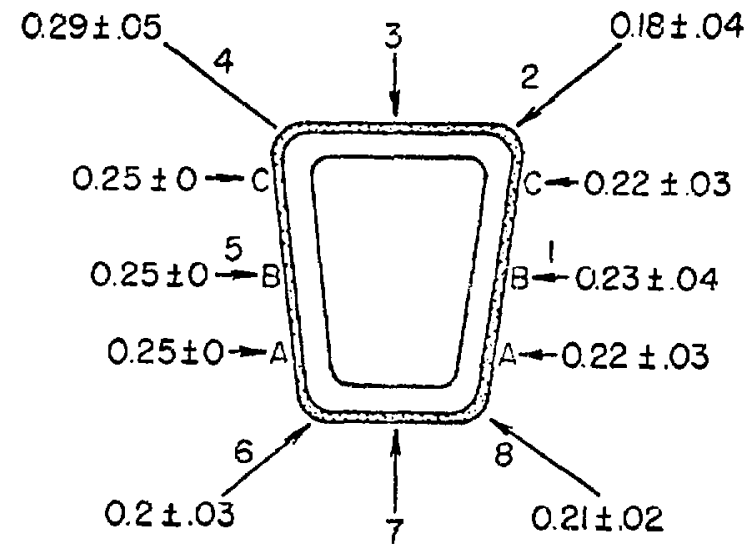

Fig. 10.

Plasma-arc sproy gun aiming points and coating thichness resulting from an 80 '; com. pleted spraving operation. the trapezoids are at different distances from its center of rotation. This process was repeated, 5 passes per corner, until all the corners had received about 10 passes. The exact number varied depending upon the behavior of the spray gun, and adjust ments were made accordingly.

At this point the coating was 80 to $90^{\prime \prime}$ ' of the desired thickness ard the sample was removed from the spraying apparatus; another une was inserted and the process repeated.

The coating thicknesses of the partially sprayed specimens were then determined. An Eddy current Dermitron was tried but failed to provide reliable data in the thickness rarge of interest. LASL Group M-1 made measurements of the coating thickness using beta backscattering for the surfaces and radiography for the corners.

Coating thicknesses were obtained at the positions designated by the letters in Fig. 10 at five stations along the length of each trapezoid. Beta backscattering was used to make measurements on the flat sides of the trapezoids, whereas radiography was used to measure the coating thicknesses on the corners. The thickness data were averaged for the five stations for each position and if the standard deviations were small the thicknesses were noted as shown in Fig. 10. The specimens were discarded if large standard deviations were encountered, which indicated a variation along the length of a sample.

The accuracy of these measurements was estimated to be about $0.05 \mathrm{~mm}$ by LASL Group M-1 and were checked $b_{y}$ sectioning severa! trapezoids at the measuring stations and examining them metallographically. Generally the values were in good agreement within the $0.05-\mathrm{mm}$ accuracy figure.

After the coating profiles of the partially sprayed trapezoids had been measured, a final spraying schedule could be selected to even out the variations in the coating thickness and to obtain the desired thickness.

The trapezoidal segment shown in Fig. 10 had been plasma-arc spraved with alumina using il passes on each corner before measuring the coating thickness. When the final spraying was being done. the plasma-arc spray gun wes depositing about 0.025 $\mathrm{mm}$ of alumina per pass. By aiming the gun at the corners, the $0.025-\mathrm{mm}$ thickness was deposited upon the corner and progressively less along the adjacent sides. Consequent ly, two passes were made with the spray gun aimed at corners 2, 6, and 8. This was enough to even out the coatings and to reach the 0.3 $m m$ thickness desired.

Figure 11 is a macrophotograph of a trapezoid that was sacrificed for examination after final spraying. It has a uniform, sound, acihcrent coating. A photomicrograph of the coating, containing about 


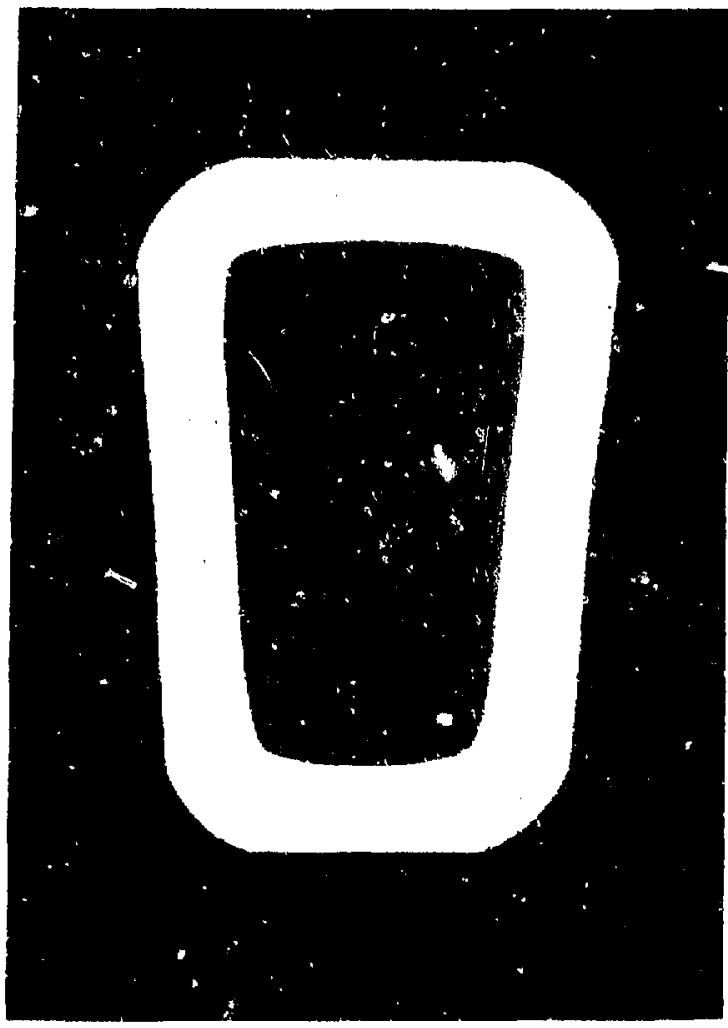

Fig. 11.

Macrophotograph of plasma-arc sprayed trapezoid, cross-sectional vieu (loX).

$20{ }^{\circ}$ porosity, is shown in Fig. 12. A scanning elec. tromicrograph is shown in Fig. 13. The surface has the typical rough porous surface produced by plasma-arc spraying including a large percentage of plate-like particles indicating that the alumina struck the substrate in a very plastic or molten condition.

Because of the relaxation of tolerances, some of the trapezoids were slightly smaller than originally specifled. To have a tight fit of the 36 trapezoids in the alumina vacuum tube, it was necessary to spray some trapezoids with slightly thicker coatings. This turned out to be convenient because some trapezoids had portions of their coatings over $0.3 \mathrm{~mm}$ thick when first measured. These were treated in the same way as the undersized ones except just enough alumina was sprayed on to even out the coating. By selecting trapezoids, it was possible to find 36 that fit precisely as desired into the alumina vacuum tube.

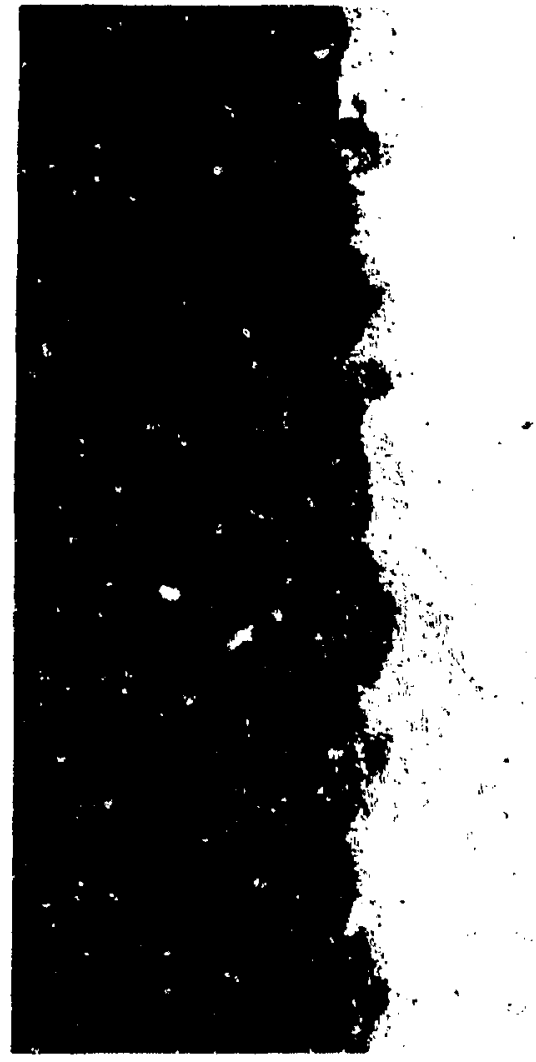

Fig. 12 .

Phutomicrograph of plasma-arc sprayed trapezoid. cross-sectional view (250X).

\section{F. Cutting the Trapezoids to Length}

The sprayed specimens were made a little longer than required to minimize any end effects that might occur during spraying. It was, therefore, necessary to cut the trapezoids to length, $500 \pm 0.05$ $\mathrm{mm}$, after coating.

Several techniques for maintaining clean surfaces during the cutoff operation were examined. Impregnation of the alumina coating in the cul area with a soluble organic and overall coating with a strippable plastic were evaluated. Both methods provided good protection from dirt and cutting fluid, but ensuring the complete removal of the protective coating, after the cutting operatirn, was difficult. At best, removing the protective coatings was tedious and time consuming.

The method finally choser worked nicely and was extremely simple. A trapezoid was put into a 


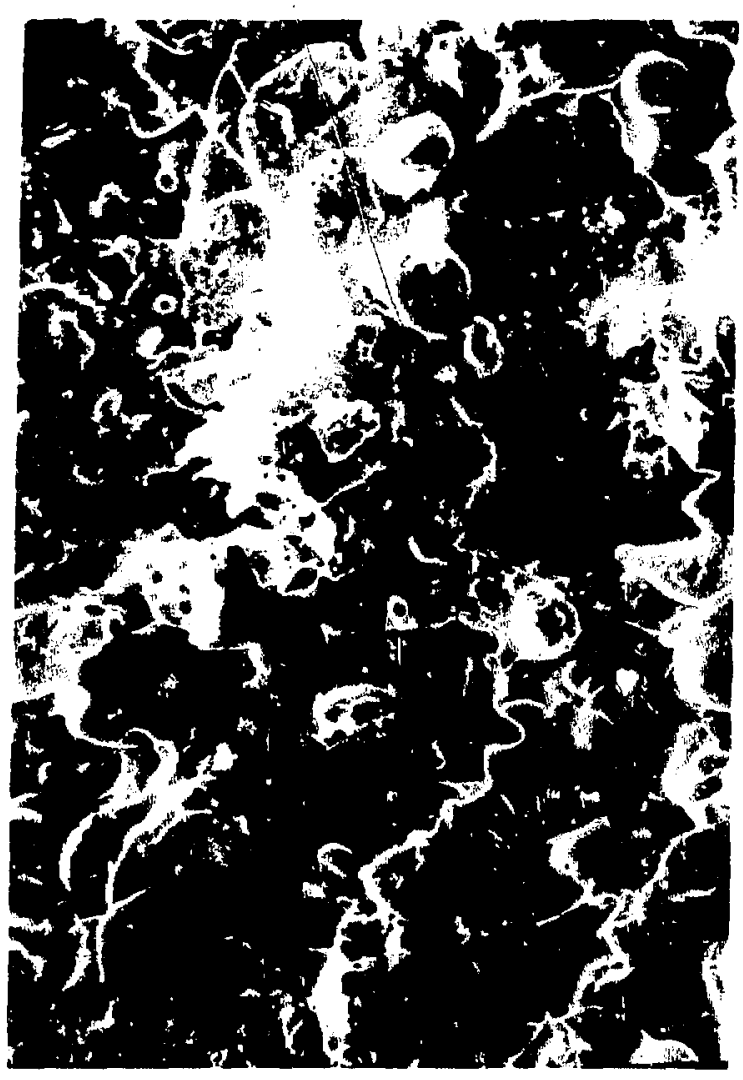

Fig. 13.

Seanning secteromicrograph of the surface of a plasma-are sprayed alumina ceated trapezoid (j(I) X).

moderately loosely fitting polyethylene bag open on both ends and the ends of the bag were taped to the trapezoid in the cut area using sicotch brand Magic Tape. By making the cut through the tape, not the bag. protection was afforded to both the immediate cut area and the rest of the trapezoid. After cutting, the bag was rinsed, dried. the tape peeled off, and the trapezoid removed.

A $100-\mathrm{mm}$-diam by $0.64-\mathrm{mm}$-thick SiC 120-grit cutoff wheel (ACM-4 AUB-120-25) was used in an SC.R controlled DuMore grinder. The wheel rotational speed was $84 \mathrm{rads} / \mathrm{s}(800 \mathrm{rpm})$, the infeed rate $0.017 \mathrm{~mm} / \mathrm{rad}(0.02 \mathrm{num} /$ revolution), anci the trapezoid was rotated at $8.4 \mathrm{rads} / \mathrm{s}(80 \mathrm{rpm})$.

\section{G. Coating the Ends of the Trapezoids}

To prevent arcing between the trapezoid segments of the discharge tube under theta-pinch conditiors. it was necessary to coat the ends of the trapezoids after they had been cut to length. Both temperature resistant plastics and plasma-arc sprayed alumina were considered.

Plastic materials were originally specified for several uses in the discharge tube. They were to be used (1) to insulate the ends of the trapezoids, (2) to insulate wire leads for instrumentation, and (3) to insulate instrumentation feed-throughs. It was also planned to degas the discharge tube at $200^{\circ} \mathrm{C}$, which severely limited the plastics that could be used.

Three promising commercial materials were evaluated. Two weit based on silicone resins and the third on polyimide resins. Differential thermal analysis (DTA) and thermai gravimetric analysis (TGA) were used to examine the stability of the plastics as a function of temperature. The TGA studies on the three materials indicated a progressive decomposition or sublimation of the two silicone materials as the temperiture increased, whereas the polyimide plastic appeared to be completely stable. DTA curves also confirmed these observations.

The polvimide was then cuated on $25.4-\mathrm{mm}$-diam stainless steel disks for evaluating their dielectric strengths. A maximum coating thickness of 0.076 $\mathrm{mm}$ could be obtained by applying about 10 coats with a baking cycle between each coat. Thicker coats tended to have an "orange-peel" surface. Measurements indicated that the polyimide had a dielectric strength of 51 to $80 \mathrm{MV} / \mathrm{m} \quad(1.3$ to 2 $\mathrm{kV} / \mathrm{mill}$. This value appeared to be adequate for the planned tests.

However, instrumentation requiring insulated leads and feed-throughs was eliminated from the first test and it was decided to eliminate all plastics from the system. Consequently, the ends of the trapezoids were coated with plasma-arc sprayed alumina.

Several experiments were conducted to obiain reasonably uniform $0.3-\mathrm{mm}$-thick end coatings without any flash or buildup of alumina or the exterior of the trapezoidal tubes' surfaces.

The method chosen employed the same spraying parameters used to spray the trapezoids and used a gun-to-work distance of $35 \mathrm{~mm}$. The tubes were arranged in an end-on position with the small side alternately placed up and down. They were separated along their long sides with $0.7-\mathrm{mm}$-thick polished shim stock, which protruded beyond the ends approximately $0.1 \mathrm{~mm}$. The tubes lined after spraying with the shims removed are shown in Fig. 14. The ends of the tubes were sprayed using six traversing passes with the spray gun focused at the upper third of the ends and six passes focused at the lower third. 


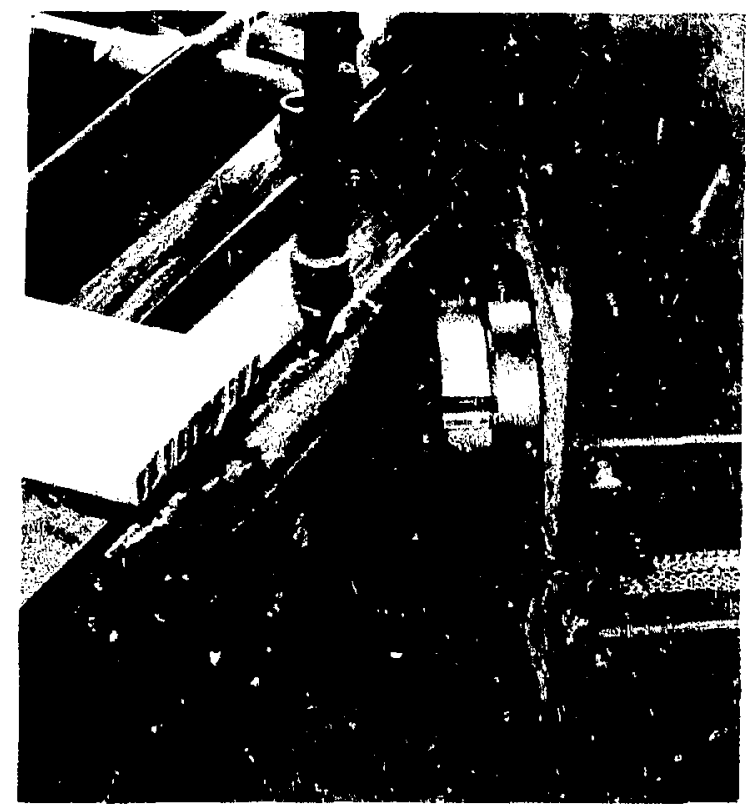

Fig. 14.

Trapezuids lined up after end spraying operation.

The bonding between the ends of the trapezoid and the alumina coating was of a poorer quality than the rest because of the small area covered and the $90^{\circ}$ transition between the end and sides of the trapezoid tubes. The end insulation is clearly the weakest link in the discharge tube and considerable care was required to prevent chipping during handling.

Fifty-seven units were end sprayed to use in the final assembly.

\section{DIELECTRIC VOLTAGE BREAKDOWN TESTING}

During the early stages of the development work, electrical ireakdown testing was done using both flat and trapezoidal-shaped specimens. We decided the tests failed to mock up the conditions $\mathrm{ks}$. countered in a theta-pinch discharge, therefore an electrical breakdown test was not used as a quality control test.

Dielectric breakdown strengths were, however, measured on a few trapezoids using the stainless steel substrate as one electrode and a braided copper cable sheathing stretched over the trapezoid as the other electrode. Measurements made in this way failed to register a sharp discontinuity between an insulating and conducting state but rather showed a gradual decrease in resistivity as the voltage increased.

\section{ASSEMBLY OF THE DISCHARGE TUBE}

The assembly of the tube was much simpler than anticipated. An assembly jig was constructed to aid in the assembly; however, it reatired a rotational movement of the trapezoid tubes to put them in place, which in turn caused darnage to the spraved alumina coatings on the trapezoid ends. We feel that a "soft" plastic jig similar to the one built would have worked.

The assembly was made finally by hand and no problems were encountered. The high-purity highfired alumina vacuum tube, which had been ground to size, was placed over one of the ceramic (highpurity, low-firted. alumina) end pieces. A dimensional drawing of the end support is shown in Fig. 15. The trapezoids were inserted one at a time into the tube and their lower ends fitted into the annular space created between the ceramic end support and vacuum tube. The last tube was the only one that received any abrasion upon assembly, and it was minor.

With all 36 trapezoids in place and held by the bottom support, it was necessary only to hold the trapezoids out against the vacuum tube to allow the top end support to be put in place. This was done by hand--a sponge might have been easier. Once the top support was in place the tube was laid on its side and the aluminum vacuum couplings used to connect it to the vacuum system were put on and secured. The tinal assembly, shown in Fig. 16, was

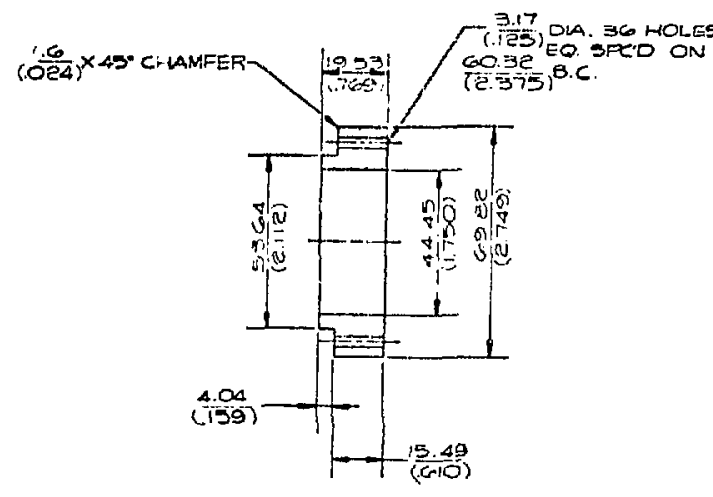

Fig. 15.

Ceramic end supports. 


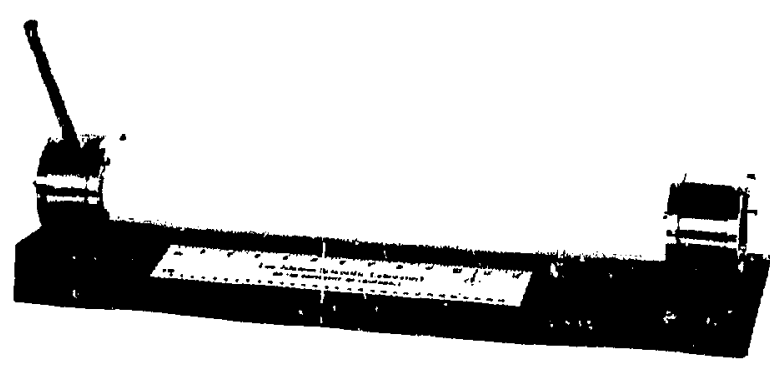

Fig. 16 .

Completed dincherese tube ready to be placed in a thera-pinch coil.

then delivered to LASL Groups (CTR-T for testing in a theta-pinch coil. A separate report will be issued on the test results.

\section{ACKNOWLEDGMENTS}

The authors sratefully acknowledge the technical assistance and support is the LASL Controlled
Thermonuclear Reactor Division; the Analytical Chemistry Group, CMB-1; the Nondestructive Testing Group, M-1; and the authors' group, the Materials Technology Group, CMB-6. The following individuals made particularly useful contributions to the program: B. L. Barthell, J. M. Burch. H M. Crane, E. E. Eaton, H. J. Fulibright. C. A. Javorsky. R. A. Krakowski, E. G. Morris, L. D. Rickerson, and D. Roybal.

\section{REFERENCES}

1. K. I. Thomassen. Ed., "Conceptual Design Study of a Scyllac Fusion Test Reactor," Los Alamos Scientific Laboratory repor: LA-6024 (January 1976).

2. "An Engineering Design Study of a Reference Theta-Pinch Reactor (K'PR)," Los Alamos Scientific Laboratory, Argonne National Laboratory report LA-5336/ANL-8019 (1974).

3. L. A. Abhatiello, Lnion Carbide and Carbon YI2 Plant, personal communication. 1974.

if U.S. GOVERNAENT PRINTING OFFICE: $1976-677-34 \% / 130$ 